\title{
ETHNIC GROUP DIFFERENCES IN IMPACTS OF FREE BUS PASSES IN ENGLAND: A NATIONAL STUDY
}

Authors:

${ }^{*}$ Richard Patterson ${ }^{a}$, Elizabeth Webb ${ }^{b}$, Jennifer S Mindell ${ }^{c}$, Christopher Millett ${ }^{d}$, Anthony A Laverty ${ }^{\mathrm{e}}$

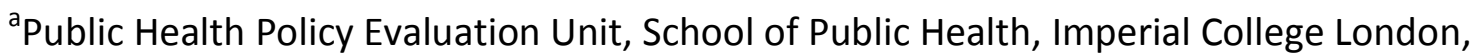
Reynolds Building, St Dunstan's Road, London, W6 8RP, UK. r.patterson@imperial.ac.uk

${ }^{\mathrm{b}}$ Department of Epidemiology and Public Health, University College London, 1-19 Torrington Place, London, WC1E 6BT, UK. elizabeth.webb@ucl.ac.uk

'Department of Epidemiology and Public Health, University College London, 1-19 Torrington Place, London, WC1E 6BT, UK. j.mindell@ucl.ac.uk

${ }^{d}$ Public Health Policy Evaluation Unit, School of Public Health, Imperial College London, Reynolds Building, St Dunstan's Road, London, W6 8RP, UK. c.millett@imperial.ac.uk

${ }^{\text {e}}$ Public Health Policy Evaluation Unit, School of Public Health, Imperial College London, Reynolds Building, St Dunstan's Road, London, W6 8RP, UK. a.laverty@imperial.ac.uk

*Corresponding author

Highlights

- A free bus pass scheme was associated with higher active travel among older people

- Larger associations were seen in minority ethnic groups

- This study reinforces the view that removing barriers to active travel can increase its use 


\section{ABSTRACT}

\section{Background}

A pass permitting free bus travel for older people (aged $\geq 60$ years) in England was introduced in 2006. There has been no examination of whether this scheme has differential effects across ethnic groups. We examined whether Black and South Asian participants were more likely to hold a bus pass and have higher associated levels of active travel than White participants.

\section{Methods}

Data come from the National Travel Survey, a nationally representative sample of the travel patterns of households in England. Using cross-sectional data from 33,344 participants eligible for a bus pass 2006-2014, we investigated ethnic differences in bus pass uptake and associations with bus use, active travel and walking $\geq 3$ times per week.

\section{Results}

Black participants were more likely to hold a bus pass (84\%) than South Asian or White participants ( $74 \%$ and $75 \%$ respectively). Black participants accumulated $56 \%$ of their active travel as part of bus journeys, compared with $29 \%$ in White and $44 \%$ in South Asian participants. Bus pass possession was associated with increased odds of bus-related active travel in all ethnic groups.

\section{Conclusions}

These findings suggest that the free bus pass scheme in England is associated with higher levels of active travel and that these may be greater among minority ethnic groups. Removing financial barriers to active travel could produce important health benefits particularly among ethnic minority groups, who have low levels of leisure-based physical activity.

Keywords: Ethnicity; active travel; older people; prevention; physical activity; public transport. 


\section{BACKGROUND}

Minority ethnic groups in England have a higher prevalence of increased adiposity than Whites. For example, persons of Black ethnicity are more likely to be overweight or obese, while South Asians are more likely to have elevated abdominal obesity than Whites (ElSayed et al., 2011). Diabetes and cardiovascular disease risk is higher among South Asian and Black groups when compared with White groups (Yusuf et al., 2001). These disparities may be partially due to lower levels of physical activity - in England minority ethnic women and men and women of South Asian ethnicity are particularly likely to be physical inactive (Higgins and Dale, 2010; Paterson and Warburton, 2010; Physical Activity Guidelines Advisory Committee, 2008).

The World Health Organization (WHO) and UK national physical activity guidelines for older people recommend 150 minutes per week of moderate to vigorous physical activity (Chief Medical Office, 2011; Physical Activity Guidelines Advisory Committee, 2008; World Health Organization, 2010) but older people have lower mean physical activity levels compared with the general adult population (Paterson and Warburton, 2010). Compared with younger adults, older people who are physically inactive face additional risks e.g. loss of independence, functional decline, falls and hip fractures (Gregg et al., 2000; Paterson and Warburton, 2010). Age related declines in physical activity are also concerning as there is evidence that the benefits of physical activity are most evident among older adults (World Health Organization, 2010).

The WHO has promoted active travel as a key intervention to combat non-communicable diseases (World Health Organization, 2002, 2012). Public transportation use has been shown to confer physical health benefits (Flint et al., 2014; Laverty et al., 2013; Liao et al., 2016) by increasing walking or cycling to and from transport hubs (Besser and Dannenberg, 2005; Patterson et al., 2018). These health benefits have been demonstrated among UK commuters, with public transport commuters having lower adiposity than those using private transport (Flint et al., 2014). With car and van use making up $78 \%$ of distance travelled in the UK, and more than $90 \%$ of non-work trips among those aged $65+$ years in the US, modal shift to more active forms of travel offers significant potential public health 
benefits (Battelle, 2000; Department for Transport, 2016). Transport patterns also differ between ethnic groups: data from 2011/15 show that Black residents of England and Wales report $31 \%$ of trips by public transport compared with $16 \%$ in Asian and $8 \%$ in White residents (Department for Transport, 2017).

In April 2006, free bus travel was introduced for those aged 60 years and over living in England. Among the eligible older population, uptake increased quickly following implementation, from around $60 \%$ in 2006 to $75 \%$ in 2009; uptake remained at $75 \%$ in the most recently available data, collected in 2015 (Department for Transport, 2016). The bus pass was primarily aimed at reducing social exclusion through access to goods and services (Department for Transport, 1998; HM Treasury, 2006), as older people are at risk of social exclusion due to factors including reduced mobility, reduced community involvement and ceasing to drive (Edwards et al., 2009; Ragland et al., 2005; Spinney et al., 2009). There is evidence that the free bus pass scheme has been successful in reducing exclusion (Jones et al., 2012; Reinhard et al., 2018) and that it additionally confers physical health benefits. Previous research has demonstrated that those with a bus pass are more likely to use active forms of travel and that bus pass possession is associated with lower adiposity in women (Coronini-Cronberg et al., 2012; Webb et al., 2016). In England, buses are the most common form of public transport and even residents of rural areas usually have some access to bus services. Buses provide access to local amenities such as shops and health services and they generally cover shorter distances than other forms of public transport. The bus pass application process is straight forward, taking place at local government buildings, and advice about applications is available from older people's charities and local authorities (Age UK, 2016).

Previous research shows that the bus pass was associated with active travel immediately following its implementation (Coronini-Cronberg et al., 2012) but did not examine any potential differences across ethnic groups. The purpose of this study was to evaluate whether Black and South Asian ethnic groups were more likely to hold a free bus pass and have higher associated levels of active travel than people of White ethnicity. We further expand on previous research by using data up to eight years after the introduction of the free bus pass. We hypothesise that the provision of free bus travel in England confers 
greater physical activity benefits among minority ethnic groups who have lower leisure based physical activity levels and worse cardiovascular disease risks.

\section{METHODS}

Full details of the England National Travel Survey (NTS) are described in detail elsewhere (Morris et al., 2015). In brief, NTS is an annual, cross-sectional survey, comprising a stratified, two-stage, random sample of private households in England. All household members are asked to take part in an interview and complete a one week travel diary. Annual response rates are $59-63 \%$.

We analysed data collected from 2006 to 2014 for participants who were eligible for the bus pass. Of the total sample of 35,843 participants, $7 \%$ were excluded: 2,447 participants who reported not leaving the house due to walking difficulties, 28 due to reporting an unusually high number of journeys in the study week (>75) and 24 due to missing ethnicity data, leaving 33,344 participants in the analysis, of whom 25,152 (75.4\%) had an older person's bus pass.

Outcomes of interest were: bus use, active travel (from the NTS travel diary) and walking three or more times per week which was ascertained during the interview. When completing the travel diary, participants recorded the mode of transportation used for each stage of any journey, additionally, the whole journey is assigned a main mode based on the mode with the greatest distance. We categorised the mode of travel for each journey stage into active (walking, cycling and public transportation such as bus or train) or not active (car, motorbike and taxi). Public transport was categorised as active as people tend to underreport short walks, such as those to access public transport (Bassett, 2000; Edwards, 2008; Golob and Meurs, 1986; Kelly et al., 2014). Therefore, this allowed us to capture the activity of all bus users, including those who did not record details of the walk to and from the bus stop. Main mode of travel for each journey was additionally categorised into bus and other, allowing a calculation of the number of active stages which took place as part of a bus 
journey. During the interview stage of NTS, participants were asked to categorise their walking frequency into one of seven categories ranging from never to three or more times per week; we dichotomised these responses into fewer than three times per week and three or more times per week. This dichotomy was chosen as walking three to five times per week has been shown to confer significant health benefits in an ageing population (Paterson and Warburton, 2010). Our primary exposure variable was having an older person's bus pass. Although initially available for all residents aged 60+, since 2010 the age of eligibility has been gradually increasing, in line with changes to the UK female state pension age and it is set to reach 66 in 2020 (Butcher, 2015). This change is accounted for in the NTS data.

Participants self-defined their ethnic group, and we subsequently categorised these as White (White British \& other White), South Asian (Indian, Pakistani and Bangladeshi), Black (Caribbean, mixed White \& Black Caribbean, Black African, mixed White \& Black African and other Black) and other (other mixed, other Asian \& any other). Although participants were able to select from at least 15 possible ethnicities, due to changing categorisations across the included survey years and low numbers in many minority ethnic groups, these have been collapsed to allow comparability. In order to investigate the effect of combining different ethnic groups, sensitivity analyses were carried out.

A range of socio-demographic and other data are collected by NTS and we used the following in these analyses: age, sex, size of conurbation of residence (categorised as: London, metropolitan built-up areas/large urban $>250 \mathrm{k}$ population, medium urban $25 \mathrm{k}-250 \mathrm{k}$ population, small/medium urban 3k-25k population, and rural), population density in persons/hectare of the household's post code sector and household access to a car. Socioeconomic status was measured using the National Statistics Socio-Economic Classification (NS-SEC) in four categories (based on current or previous employment) and home ownership.

\subsection{Analysis}

First, we summarised the socio-demographic and other characteristics of the study population separately by ethnic group. For those participants with at least one stage 
classified as active, we examined levels of bus pass possession and the amount of bus use and active travel.

Second, we investigated the association between bus pass possession and each of: active travel, bus travel, and active travel as part of a bus journey. Due to the large numbers of participants who did no active or bus travel in the diary week, we employed a zero-inflated negative binomial model in order to take account of the excess zeros in the data (Long and Freese, 2005). This method separately models the odds ratio (OR) for making any journeys (the logistic element) and also the incident rate ratio (IRR) of the numbers of journeys made (the negative binomial element). We used an interaction term between ethnicity and bus pass possession to examine whether the effects of having a bus pass on our outcomes of interest were similar across ethnic groups, and used White participants with a bus pass as the reference category.

Finally, we used a logistic regression model to examine the association between bus pass possession and walking three or more times per week, adjusting for the same covariates listed above.

Complete case analysis gave an analytical sample of 33,267 for the zero inflated negative binomial models and 33,176 for the logistic regression analysis. The NTS complex survey design was accounted for in our statistical methods which additionally used survey weights provided by NTS to take account of non-response and differences in travel diary completion across days of the week (Morris et al., 2015).

Sensitivity analyses were carried out in which Indian participants were separated from the Pakistani and Bangladeshi South Asian participants and the Black group was restricted to Black Caribbean and mixed White \& Black Caribbean. We also restricted the categorisation of active stages to walking and cycling in order to investigate the impact of including public transport stages as active stages. Finally, as a high proportion of minority ethnic older people reside in London and because London has greater provision of public transport than most other areas of England, all of which can be accessed free of charge with the bus pass 
(Freedom Pass in London), we investigate the influence of these factors by conducting analysis with London residents excluded.

\section{RESULTS}

Characteristics of the sample are shown in Table 1. 96\% of participants were White, similar to national figures in this age group (Office for National Statistics, 2011). (Table 1) Black participants were more likely to hold a bus pass (84\%) than South Asian or White participants ( $74 \%$ and $75 \%$ respectively, $p<0.001$ ). White participants were less likely to live in London or other large conurbations: $12 \%$ of White participants were London residents compared with $51 \%$ of South Asian participants and $61 \%$ of Black participants $(p<0.001)$. Black participants were more likely to live in densely populated areas: $31 \%$ in areas with $75+$ persons per hectare compared with $3 \%$ of White participants $(p<0.001) .51 \%$ of Black participants had access to a car compared with $80 \%$ of South Asian and $77 \%$ of White participants $(p<0.001)$. Home ownership was higher in South Asian participants (87\%) than in Black participants $(64 \%, p<0.001)$.

\subsection{Patterns of Active Travel}

Table 2 shows the percentage of participants who did any active travel in the diary week along with details of active and bus travel levels. (Table 2) Approximately 50\% of White and South Asian participants did any active travel, compared with $72 \%$ of Black participants. Levels of bus pass possession among those who did any active travel were consistent across ethnic groups: $85 \%$ of White and South Asian participants and $89 \%$ of Black participants ( $p$ for difference $=0.186$ ). The median number of journey stages by bus per week was four in Black participants and two in South Asian and White participants $(p<0.001)$. A similar pattern was observed with active stages as part of a bus journey, with a median of four among Black participants, two in South Asians and one in White participants. The overall number of active travel stages across the diary week was 12 in South Asian participants and eight in Black and White participants $(p<0.001)$. The proportion of overall active stages 
which were part of bus journeys was highest in Black participants (56\%) and lowest in White participants (29\%).

\subsection{Bus Pass Possession and Active Travel}

Results of zero inflated negative binomial regression analyses are shown in Table 3. (Table 3) The odds of doing any bus travel were higher in bus pass holders than non-holders in each ethnic group. For example, White participants without a bus pass had an adjusted odds ratio (AOR) of 0.09 [95\% $\mathrm{Cl}=0.08,0.10]$, compared with bus pass holders. Bus pass holders in each of the minority ethnic groups did a greater number of bus trips than White bus pass holders: IRR=1.33 $[1.16,1.53]$ and IRR=1.22 $[1.08,1.37]$ in South Asian and Black participants respectively.

Bus pass holders were more likely to have active travel stages as part of a bus journey than non-holders in each ethnic group (e.g. in South Asian non-pass holders AOR=0.06 [0.03, 0.13] compared with $A O R=0.93[0.68,1.27]$ for bus pass holders). In addition, South Asian bus pass holders carried out more active travel as part of bus journeys than their equivalent White bus pass holders (IRR=1.38 $[1.09,1.75])$. A comparison of active stages during bus journeys between ethnic groups is shown in Figure 1.

The odds of doing any active travel were higher among bus pass holders than non-holders in each ethnic group (e.g. among Black participants $A O R=0.38[0.21,0.68]$ in non-bus pass holders and AOR=1.21 $[0.84,1.73]$ in bus pass holders). Of those participants with a bus pass, South Asians $(A O R=0.60[0.46,0.78])$ were less likely to do any active travel than White participants. In White and Black participants, those with a bus pass did a greater amount of active travel, this difference was not evident in South Asian participants. For those who had a bus pass, the amount of active travel accumulated did not vary between ethnic groups $(\mathrm{IRR}=0.86[0.68,1.08]$ for South Asian participants and IRR=0.82 [0.63, 1.07] for Black participants).

Overall, $34 \%$ of the sample walked three times per week or more. The percentage of participants who reported walking three or more times per week was similar in all ethnic groups at 29\%, 31\% and 34\% in Black, South Asian and White participants respectively 
$(p=0.061)$. Bus pass possession was only associated with higher walking frequency in White participants ( $A O R=0.69[0.65,0.73]$ for those without a bus pass). The odds of walking three or more times per week did not vary across ethnic groups among bus pass holders or nonholders.

Figure 1. Active Stages as Part of Bus Journeys

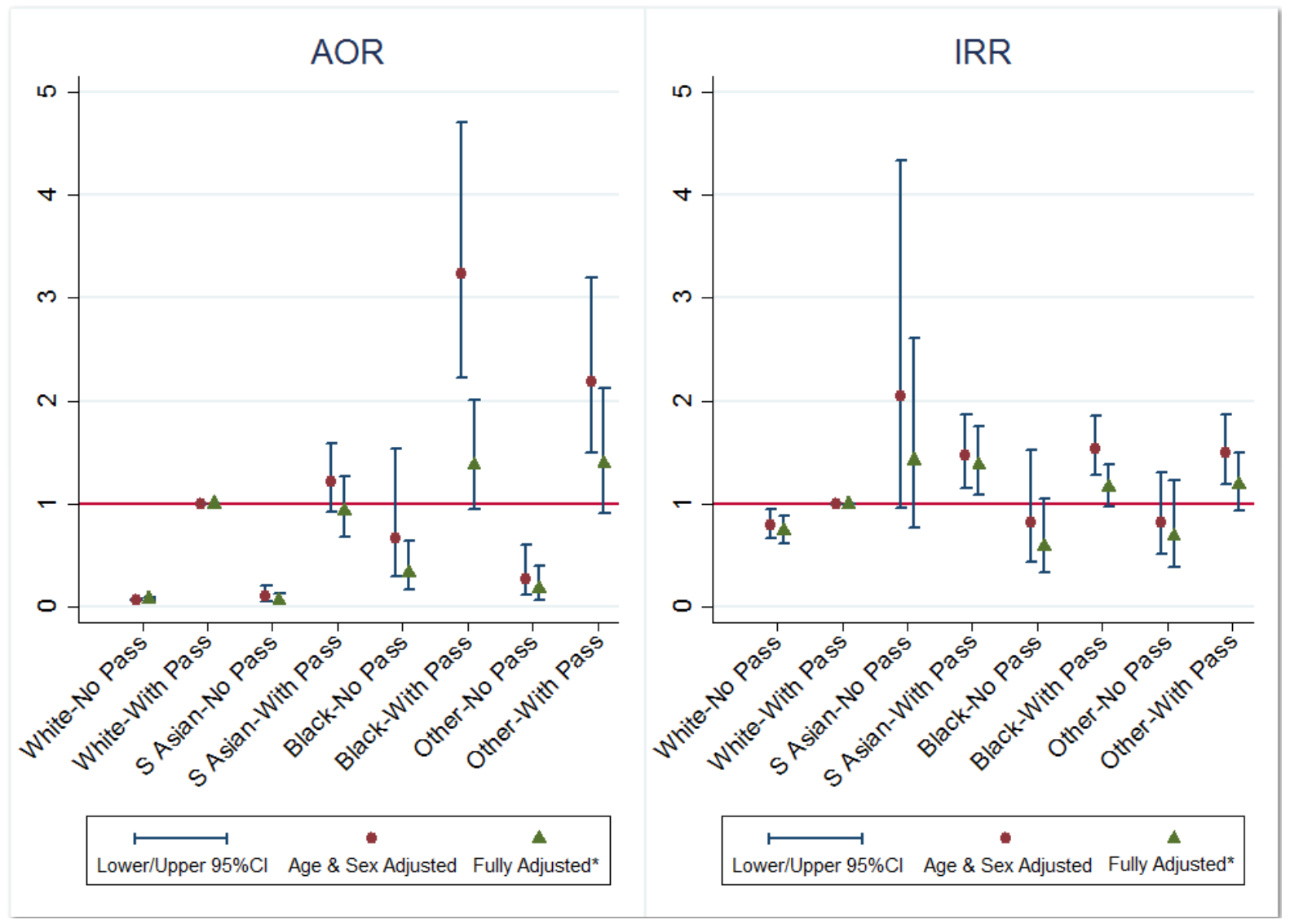

1 - indicates the reference level of white participants with a bus pass

*Covariates: Age (continuous), sex, size of area of residence, access to a car, National Statistics Socio-Economic Classification (NSSEC), population density of household's post code sector (continuous) and home ownership. 


\subsection{Sensitivity Analyses}

Tables A1-3 in Appendix A present the results of sensitivity analyses to investigate the effects of combining ethnic groups. These suggest that there are slight differences in travel patterns between Indian participants and Pakistani and Bangladeshi participants, although results for the re-categorised Black group were similar. Low numbers of participants preclude more definitive interpretation of these analyses.

Additional sensitivity analyses are presented in Appendix Tables A4-A7. The main analysis was repeated with the year of data collection included as a covariate, however, this had only very minor effects and didn't affect direction or size of associations. Models adjusted only for age and sex show that the addition of potential confounders to the regression model led to some attenuation of the results, with reduced association sizes, for example, Black bus pass holders had an AOR for any bus travel of $2.79(2.09,3.73)$ compared with $1.33(0.99,1.80)$ in the fully adjusted analysis. Excluding London residents led to some individual changes in results and loss of statistical significance, for example, Black bus pass holders no longer accumulated more active stages than non-holders. Restricting the categorisation of active to walking and cycling also led to some loss of statistical significance, to the extent that the analysis of active stages as part of a bus journey did not have enough data points to converge on estimates. However, where analyses were possible, the overall conclusions were unaffected.

\section{DISCUSSION}

These findings confirm previous research (Coronini-Cronberg et al., 2012; Webb et al., 2016; Webb et al., 2012) that free bus passes are associated with greater bus use and higher levels of active travel as part of bus journeys and additionally suggest that there may be larger effects in minority ethnic groups which persist after adjustment for markers of socioeconomic status. Minority ethnic groups are also more likely to hold and use free bus passes than Whites.

\subsection{Strengths and Limitations}


This is the first investigation into ethnic differences in the impact of the older person's free bus pass in England. This study used data from a large nationally representative survey of travel patterns in England. Our sample was representative of the general population aged 60 years and older in England in terms of age, sex and ethnicity (Office for National Statistics, 2011). NTS collects detailed travel pattern data from respondents along with socio-demographic data and the response rate is comparable with other national surveys (Mindell et al., 2015; Morris et al., 2015). However, this study does have some limitations which should be considered. The cross-sectional nature of this study means that causation cannot be attributed, and reverse causality is a possibility. The association between having a bus pass and active travel may be explained by physically active individuals being more likely to apply for a free bus pass. NTS data is self-reported and thus subject to reporting error, however the use of a travel diary to collect travel data should minimise errors in the reporting of travel data. While we have no evidence to suggest that non-response is associated with holding a bus pass or active travel habits, we cannot rule out bias of this kind. Low numbers of participants in the minority ethnic groups precluded analyses of more granular ethnic groups than used here, and additionally led to estimates for minority ethnic groups which lacked some statistical precision. Our sensitivity analyses suggest that more detailed data with larger numbers of minority ethnic participants would be needed to disentangle these relationships more fully. This could potentially be done in the future when more waves of NTS data are available or with specific data collections.

We have attempted to take into account the differences in ethnic make-up and access to bus services seen between larger, more population-dense urban areas, such as London, and more rural areas. There was some variation in the provision of free bus passes before and after the introduction of the free bus pass scheme in 2006. Some large metropolitan areas provided free local bus travel to older residents prior to the rollout of the national scheme (Kelly, 2011). Following implementation, some areas have seen higher than average uptake, including large cities such as London, where the bus pass also covers other travel modes such as underground trains (Coronini-Cronberg et al., 2012). While we were unable to assess if policies before 2006 had impacts on free bus pass uptake we did control for the population density of households' postcode sector and the size of their conurbation of 
residence, to account for potential differences in public transport provision. However, it is possible that some residual confounding remains.

Additionally, our classification of active stages includes those where participants were on the bus. This is because a large proportion of participants did not record how they accessed bus travel. Nonetheless, these issues are relevant only to two out of the four outcomes (total active stages and active stages as part of bus trips) and all four outcomes together give a rounded picture of associations between the bus pass and active travel.

\subsection{Policy Implications}

Improved access to transport can contribute to improved health behaviours and address the social determinants of health (Secretary's Advisory Committee on National Health Promotion and Disease Prevention Objectives for 2020, 2010). For example, improved access to transportation may address health inequalities by facilitating access to social networks and services such as health care (Marmot et al., 2010; Secretary's Advisory Committee on National Health Promotion and Disease Prevention Objectives for 2020, 2010). It should also be noted that the majority of the ethnic minority participants in this study live in more densely populated areas which are likely to be better served by public transport. While the extent of this is not known, it does suggest that provision of services may be behind some of the health inequality reducing effects we see here. Alongside enabling increased access to services and social networks, policies promoting active forms of travel may confer physical health benefits from increasing levels of transport-associated physical activity. While active travel constitutes just one domain of total physical activity, evidence suggests that those who use active travel modes have higher levels of total physical activity than those who do not (Hamer and Chida, 2008; Wanner et al., 2012).

Universal benefits, such as the free bus pass, have the potential for high levels of uptake. While there is some uncertainty around whether the free bus pass scheme in England reduces the cost for those already travelling by bus or encourages mode switching, there is growing evidence that use of public transportation can confer considerable health benefits 
in terms of reduced adiposity and improved mobility in ageing (Flint and Cummins, 2016; Webb et al., 2016). Older people are a particularly important group for any such changes: issues such as driving cessation among older people lead to difficulties accessing services and recreation and are associated with depression and declines in physical and social functioning (Edwards et al., 2009; Marottoli et al., 1997; Marottoli et al., 2000; Ragland et al., 2005; Taylor and Tripodes, 2001). In an ageing population with increasing levels of vision impairment, dementia and other age-related causes of driving cessation, encouraging bus use to aid a gradual transition away from car use can improve the experience of driving cessation and enable continued mobility for people who would otherwise be excluded from transport due to ageing (Janke, 1994; Musselwhite and Shergold, 2013).

\section{CONCLUSION}

In 2006, England introduced a free bus pass scheme for older people, which previous research found to be associated with more physically active forms of travel. Here we found that bus pass possession was associated with increased bus use and active travel and that these associations were greater in minority ethnic groups. Public transport is important because it can play a role in increasing physical activity among those who would not consider cycling or walking an entire journey and who may not engage in other forms of leisure based physical activity. This includes some ethnic minority groups who, in addition to lower levels of leisure-time physical activity, have greater cardiovascular risk. Some of the associations we have found may be driven by greater provision of public transport in areas with greater numbers of ethnic minority residents. However, as ethnic minorities in England predominantly reside in large cities, public transport is a potentially effective mechanism to address ethnic inequalities.

The free bus pass is an example of a policy implemented primarily for non-health reasons which has additional benefits for public health. There are a wide range of factors which may 
be helpful in addressing the epidemic of inactivity related ill-health, including urban design features and financial incentives such as the free bus pass (Hill, 2009; King et al., 2011). The accumulation of small changes in population behaviour may be more sustainable than advocating large individual changes to diet and physical activity (Hill, 2009). In conclusion, this study reinforces the view that removing barriers to active travel can increase its use, and that these effects may be most marked in ethnic minority groups with low levels of leisure based physical activity. 


\section{TABLES}

Table 1 - Characteristics of NTS participants from 2006 to 2014 who were eligible for a free older peoples bus pass (aged 60-99) by ethnic group

\begin{tabular}{|c|c|c|c|c|c|c|}
\hline & White & South Asian & Black & Other & $p$-value ${ }^{a}$ & All \\
\hline & N. $/ \%$ & N. / \% & N. $/ \%$ & N. / \% & & N. / \% \\
\hline All participants & 32030 & 557 & 403 & 354 & & 33344 \\
\hline Mean age & 71.0 & 69.3 & 70.2 & 69.0 & & 70.9 \\
\hline \multicolumn{7}{|l|}{ Age group } \\
\hline $60-64$ & $25 \%$ & $28 \%$ & $26 \%$ & $33 \%$ & $p<0.001$ & $25 \%$ \\
\hline $65-69$ & $24 \%$ & $29 \%$ & $29 \%$ & $27 \%$ & & $24 \%$ \\
\hline $70-75$ & $19 \%$ & $21 \%$ & $18 \%$ & $20 \%$ & & $19 \%$ \\
\hline $75+$ & $31 \%$ & $22 \%$ & $27 \%$ & $19 \%$ & & $31 \%$ \\
\hline \multicolumn{7}{|l|}{ Sex } \\
\hline Male & $47 \%$ & $52 \%$ & $45 \%$ & $49 \%$ & $p=0.076$ & $47 \%$ \\
\hline Female & $53 \%$ & $48 \%$ & $55 \%$ & $51 \%$ & & $53 \%$ \\
\hline \multicolumn{7}{|l|}{ Geographical area } \\
\hline $\begin{array}{l}\text { London } \\
\text { >250k people }\end{array}$ & $12 \%$ & $51 \%$ & $61 \%$ & $59 \%$ & $p<0.001$ & $13 \%$ \\
\hline (except London) & $26 \%$ & $31 \%$ & $26 \%$ & $13 \%$ & & $26 \%$ \\
\hline 50k-250k people & $20 \%$ & $11 \%$ & $7 \%$ & $17 \%$ & & $19 \%$ \\
\hline \multicolumn{7}{|l|}{$\begin{array}{l}\text { Area population density } \\
\text { persons/hectare }\end{array}$} \\
\hline $0-14.99$ & $50 \%$ & $12 \%$ & $9 \%$ & $17 \%$ & $p<0.001$ & $49 \%$ \\
\hline $15-29.99$ & $24 \%$ & $13 \%$ & $17 \%$ & $20 \%$ & & $24 \%$ \\
\hline $30-49.99$ & $18 \%$ & $34 \%$ & $21 \%$ & $23 \%$ & & $18 \%$ \\
\hline $50-74.99$ & $5 \%$ & $23 \%$ & $22 \%$ & $19 \%$ & & $6 \%$ \\
\hline $75+$ & $3 \%$ & $18 \%$ & $31 \%$ & $21 \%$ & & $4 \%$ \\
\hline \multicolumn{7}{|l|}{ Car access } \\
\hline Have car access & $77 \%$ & $80 \%$ & $51 \%$ & $67 \%$ & $\mathrm{p}<0.001$ & $77 \%$ \\
\hline No car access & $23 \%$ & $20 \%$ & $49 \%$ & $33 \%$ & & $23 \%$ \\
\hline \multicolumn{7}{|c|}{ NS Socio-Economic Classification (current or last job) } \\
\hline Managerial & $44 \%$ & $46 \%$ & $36 \%$ & $51 \%$ & $p<0.001$ & $44 \%$ \\
\hline Intermediate & $23 \%$ & $20 \%$ & $17 \%$ & $21 \%$ & & $23 \%$ \\
\hline Routine and manual & $30 \%$ & $29 \%$ & $41 \%$ & $23 \%$ & & $30 \%$ \\
\hline Not classified & $2 \%$ & $6 \%$ & $6 \%$ & $5 \%$ & & $3 \%$ \\
\hline \multicolumn{7}{|l|}{ Home ownership } \\
\hline Owns & $82 \%$ & $87 \%$ & $64 \%$ & $70 \%$ & $p<0.001$ & $82 \%$ \\
\hline Rents & $18 \%$ & $13 \%$ & $36 \%$ & $30 \%$ & & $18 \%$ \\
\hline \multicolumn{7}{|l|}{ Walking frequency } \\
\hline Walk < 3x / week & $66 \%$ & $69 \%$ & $71 \%$ & $64 \%$ & $p=0.061$ & $66 \%$ \\
\hline Walk $\geq 3 x$ /week & $34 \%$ & $31 \%$ & $29 \%$ & $36 \%$ & & $34 \%$ \\
\hline \multicolumn{7}{|l|}{ Bus pass possession } \\
\hline No bus pass & $25 \%$ & $26 \%$ & $16 \%$ & $21 \%$ & $p<0.001$ & $25 \%$ \\
\hline Have a bus pass & $75 \%$ & $74 \%$ & $84 \%$ & $79 \%$ & & $75 \%$ \\
\hline
\end{tabular}

NTS=National Travel Survey, NS=National Statistics. a- Pearson's Chi-squared test 
Ethnicity categorisation: White (White British and other White), South Asian (Indian, Pakistani and Bangladeshi), Black (Black African, mixed White \& Black African, Black Caribbean, mixed White \& Black Caribbean and other Black) and other (other mixed, other Asian and any other).

Table 2 - Travel patterns of those participants who did any active travel

\begin{tabular}{|c|c|c|c|c|c|}
\hline & White & South Asian & Black & Other & p-value \\
\hline $\mathrm{N}$ who did any active travel (\%) & 17619 (55\%) & $284(51 \%)$ & $291(72 \%)$ & $226(64 \%)$ & $p<0.001^{a}$ \\
\hline$\%$ with a bus pass & $85 \%$ & $85 \%$ & $89 \%$ & $88 \%$ & $p=0.186^{a}$ \\
\hline Bus travel* & $2(0-4)$ & $2(0-6)$ & $4(2-8)$ & $4(0-8)$ & $p<0.001^{b}$ \\
\hline Active travel as part of a bus journey* & $1(0-4)$ & $2(0-8)$ & $4(1-9)$ & $4(0-8)$ & $p<0.001^{b}$ \\
\hline Total active travel* & $8(4-16)$ & $12(4-17)$ & $8(4-17)$ & $11(4-18)$ & $\mathrm{p}<0.001^{\mathrm{b}}$ \\
\hline $\begin{array}{l}\% \text { of total active stages which are part } \\
\text { of a bus journey }\end{array}$ & $29 \%$ & $44 \%$ & $56 \%$ & $46 \%$ & $p<0.001^{a}$ \\
\hline \multicolumn{6}{|c|}{$\begin{array}{l}\text { Ethnicity categorisation: White (White British and other White), South Asian (Indian, Pakistani and Bangladeshi), Black } \\
\text { (Black African, mixed White \& Black African, Black Caribbean, mixed White \& Black Caribbean and other Black) and other } \\
\text { (other mixed, other Asian and any other). }\end{array}$} \\
\hline \multicolumn{6}{|c|}{ *median number of stages/week (interquartile range) } \\
\hline a - Pearson's Chi-squared test, ${ }^{b}$ - Krusk & /allis test & & & & \\
\hline
\end{tabular}


Table 3 - Association between holding a bus pass and travel mode by ethnic group

\begin{tabular}{|c|c|c|c|c|c|c|c|}
\hline \multirow{3}{*}{ Bus Stages } & White & \multicolumn{2}{|c|}{ South Asian } & \multicolumn{2}{|r|}{ Black } & \multicolumn{2}{|c|}{ Other } \\
\hline & AOR/IRR (95\% Cl) & \multicolumn{2}{|c|}{ AOR/IRR (95\% Cl) } & \multicolumn{2}{|c|}{ AOR/IRR (95\% CI) } & \multicolumn{2}{|c|}{ AOR/IRR (95\% CI) } \\
\hline \multirow{2}{*}{\multicolumn{8}{|c|}{ AOR of doing any travel }} \\
\hline & & & & & & & \\
\hline No Bus Pass & $0.09 * * * \quad(0.08,0.10)$ & $0.08 * * *$ & $(0.04,0.16)$ & $0.31 * * *$ & $(0.17,0.57)$ & $0.17 * * *$ & $(0.08,0.36)$ \\
\hline With Bus Pass & $1.00 \quad$ (ref) & 0.87 & $(0.66,1.13)$ & 1.33 & $(0.99,1.80)$ & 1.14 & $(0.82,1.58)$ \\
\hline \multicolumn{8}{|c|}{ IRR of amount of travel } \\
\hline No Bus Pass & $(0.76,0.96)$ & 1.06 & $(0.65,1.75)$ & 0.96 & $(0.55,1.68)$ & 1.00 & $(0.57,1.76)$ \\
\hline With Bus Pass & (ref) & $1.33^{* * *}$ & $(1.16,1.53)$ & $1.22 * *$ & $(1.08,1.37)$ & $1.29 * * *$ & $(1.12,1.48)$ \\
\hline \multicolumn{8}{|c|}{ Active stages as part of a bus trip } \\
\hline \multicolumn{8}{|c|}{ AOR of doing any travel } \\
\hline No Bus Pass & $0.08 * * * \quad(0.07,0.09)$ & $0.06 * * *$ & $(0.03,0.13)$ & $0.33^{* *}$ & $(0.17,0.64)$ & $0.17^{* * *}$ & $(0.07,0.39)$ \\
\hline With Bus Pass & $1.00 \quad$ (ref) & 0.93 & $(0.68,1.27)$ & 1.38 & $(0.95,2.01)$ & 1.39 & $(0.91,2.12)$ \\
\hline \multicolumn{8}{|c|}{ IRR of amount of travel } \\
\hline No Bus Pass & $0.74 * * * \quad(0.62,0.88)$ & 1.42 & $(0.77,2.61)$ & 0.58 & $(0.33,1.05)$ & 0.69 & $(0.38,1.23)$ \\
\hline With Bus Pass & $1.00 \quad$ (ref) & $1.38^{* *}$ & $(1.09,1.75)$ & 1.16 & $(0.97,1.38)$ & 1.18 & $(0.93,1.49)$ \\
\hline \multicolumn{8}{|c|}{ Total Active Stages } \\
\hline \multicolumn{8}{|c|}{ AOR of doing any travel } \\
\hline No Bus Pass & $0.29 * * * \quad(0.27,0.31)$ & $0.16^{* * *}$ & $(0.11,0.25)$ & $0.38 * *$ & $(0.21,0.68)$ & $0.24 * * *$ & $(0.14,0.41)$ \\
\hline With Bus Pass & $1.00 \quad$ (ref) & $0.60 * * *$ & $(0.46,0.78)$ & 1.21 & $(0.84,1.73)$ & 1.05 & $(0.74,1.50)$ \\
\hline \multicolumn{8}{|c|}{ IRR of amount of travel } \\
\hline No Bus Pass & $(0.90,0.98)$ & 1.17 & $(0.88,1.55)$ & $0.46 * * *$ & $(0.30,0.70)$ & 0.85 & $(0.59,1.23)$ \\
\hline With Bus Pass & (ref) & 1.03 & $(0.88,1.20)$ & 0.88 & $(0.76,1.01)$ & 0.95 & $(0.83,1.10)$ \\
\hline \multicolumn{8}{|c|}{ Walking $\geq 3$ times/week } \\
\hline \multicolumn{8}{|c|}{ AOR } \\
\hline No Bus Pass & $0.69 * * * \quad(0.65,0.73)$ & $0.46^{* * *}$ & $(0.30,0.70)$ & $0.43^{*}$ & $(0.22,0.82)$ & $0.43 * *$ & $(0.24,0.79)$ \\
\hline With Bus Pass & $1.00 \quad$ (ref) & 0.86 & $(0.68,1.08)$ & 0.82 & $(0.63,1.07)$ & 1.04 & $(0.78,1.39)$ \\
\hline \multicolumn{8}{|c|}{$\begin{array}{l}\text { Ethnicity categorisation: White (White British and other White), South Asian (Indian, Pakistani and Bangladeshi), Black } \\
\text { (Black African, mixed White \& Black African, Black Caribbean, mixed White \& Black Caribbean and other Black) and other } \\
\text { (other mixed, other Asian and any other). } \\
\text { Covariates: Age (continuous), sex, size of area of residence, access to a car, National Statistics Socio-Economic Classification } \\
\text { (NS-SEC), population density of household's post code sector (continuous) and home ownership. }\end{array}$} \\
\hline \multicolumn{8}{|c|}{ AOR-adjusted odds ratio, IRR-incident rate ratio. } \\
\hline
\end{tabular}




\section{Declarations}

\section{Ethics approval and consent to participate}

This was a secondary analysis of anonymised data, therefore ethnical approval was not required. We had approval from the UK Data Service to use NTS data, which is publically available and de-identified.

\section{Consent for publication}

Not applicable

\section{Availability of data and material}

NTS data is available from the UK data service at https://www.ukdataservice.ac.uk/

\section{Competing interests}

The authors declare that they have no competing interests.

\section{Funding}

This work was supported by: the UK Department of Health Policy Research Programme (PRR5-0213-25006), the National Institute of Health Research (RP 2014-04-032) and the ESRC International Centre for Lifecourse Studies (ES/J019119/1). The views expressed are those of the authors and not necessarily the views of these funders.

\section{Authors' contributions}

A. Laverty, C. Millett and R. Patterson conceived the idea for the study. A. Laverty and E. Webb supervised R. Patterson in carrying out the data analysis. R. Patterson and A. Laverty drafted the article. All authors contributed to re-drafting and approved the final manuscript.

\section{Acknowledgements}

Not applicable 


\section{REFERENCES}

Age UK, 2016. Public Transport Concessions. http://www.ageuk.org.uk/money-matters/claimingbenefits/public-transport-and-concessions/transport-concessions-older-people/ (accessed 9 May, 2017)

Bassett, D., 2000. Measurement of daily walking distance-questionnaire versus pedometer. Med Sci Sports Exerc 32, 1018-1023.

Battelle, 2000. Travel Patterns of People of Color. U.S. Department of Transportation Federal Highway Administration. https://www.fhwa.dot.gov/ohim/trvpatns.pdf (accessed 15 April, 2016) Besser, L.M., Dannenberg, A.L., 2005. Walking to public transit: steps to help meet physical activity recommendations. Am J Prev Med 29, 273-280. http://dx.doi.org/10.1016/j.amepre.2005.06.010 Butcher, L., 2015. Concessionary bus fare - Briefing paper SN01499. House of Common Library. https://www.gov.uk/apply-for-elderly-person-bus-pass (accessed 4 April, 2016) Chief Medical Office, 2011. Physical activity guidelines for older Adults (65+ Years). Department of Health, .

https://www.gov.uk/government/uploads/system/uploads/attachment data/file/213741/dh 12814 6.pdf (accessed 26 February, 2016)

Coronini-Cronberg, S., Millett, C., Laverty, A.A., Webb, E., 2012. The impact of a free older persons' bus pass on active travel and regular walking in England. Am J Public Health 102, 2141-2148.

http://dx.doi.org/10.2105/AJPH.2012.300946

Department for Transport, 1998. A new deal for transport: better for everyone - white paper. http://webarchive.nationalarchives.gov.uk/20080306022529/http:/www.dft.gov.uk/about/strategy/ whitepapers/previous/anewdealfortransportbetterfo5695 (accessed 22 April, 2016)

Department for Transport, 2016. NTS Statistical Tables.

https://www.gov.uk/government/collections/national-travel-survey-statistics (accessed 12 April, 2016)

Department for Transport, 2017. Ethnicity facts and Figures: Travel by distance, trips, type of transport and purpose. https://www.ethnicity-facts-figures.service.gov.uk/culture-andcommunity/transport/travel-by-distance-trips-type-of-transport-and-purpose/latest (accessed 5 June, 2018)

Edwards, J.D., Lunsman, M., Perkins, M., Rebok, G.W., Roth, D.L., 2009. Driving Cessation and Health Trajectories in Older Adults. The Journals of Gerontology: Series A 64A, 1290-1295.

https://doi.org/10.1093/gerona/glp114

Edwards, R.D., 2008. Public transit, obesity, and medical costs: assessing the magnitudes. Prev Med 46, 14-21. https://doi.org/10.1016/i.ypmed.2007.10.004

El-Sayed, A.M., Scarborough, P., Galea, S., 2011. Ethnic inequalities in obesity among children and adults in the UK: a systematic review of the literature. Obes Rev 12, e516-534.

http://dx.doi.org/10.1111/j.1467-789X.2010.00829.x

Flint, E., Cummins, S., 2016. Active commuting and obesity in mid-life: cross-sectional, observational evidence from UK Biobank. The Lancet Diabetes \& Endocrinology 4, 420-435.

http://dx.doi.org/10.1016/s2213-8587(16)00053-x

Flint, E., Cummins, S., Sacker, A., 2014. Associations between active commuting, body fat, and body mass index: population based, cross sectional study in the United Kingdom. BMJ 349, g4887.

http://dx.doi.org/10.1136/bmj.g4887

Golob, T.T., Meurs, H., 1986. Biases in response over time in a seven-day travel diary. Transportation 13, 163-181. https://doi.org/10.1007/bf00165546

Gregg, E.W., Pereira, M.A., Caspersen, C.J., 2000. Physical activity, falls, and fractures among older adults: a review of the epidemiologic evidence. J Am Geriatr Soc 48, 883-893.

Hamer, M., Chida, Y., 2008. Active commuting and cardiovascular risk: a meta-analytic review. Prev

Med 46, 9-13. https://doi.org/10.1016/j.ypmed.2007.03.006 
Higgins, V., Dale, A., 2010. Ethnic Differences in Physical Activity and obesity, working paper. Cathie Marsh Centre for Census and Survey Research.

https://lemosandcrane.co.uk/resources/University\%20of\%20Manchester\%20-

\%20Ethnic\%20differences\%20in\%20physical\%20activity\%20and\%20obesity.pdf (accessed 8 July, 2016)

Hill, J.O., 2009. Can a small-changes approach help address the obesity epidemic? A report of the Joint Task Force of the American Society for Nutrition, Institute of Food Technologists, and International Food Information Council. Am J Clin Nutr 89, 477-484.

http://dx.doi.org/10.3945/aicn.2008.26566

HM Treasury, 2006. Budget 2006. The Stationery Office.

https://www.gov.uk/government/publications/red-book-2006-budget (accessed 27 June, 2018) Janke, M.K., 1994. Age related disabilities that may impair driving and their assessment. Research and Development Section, Division of Program and Policy Administration, California Department of Motor Vehicles. https://www.dmv.ca.gov/portal/wcm/connect/3fbabce2-511b-4ec5-9185-

d98f566d56f1/S6-156.pdf?MOD=AJPERES\&CONVERT TO=url\&CACHEID=3fbabce2-511b-4ec5-9185d98f566d56f1 (accessed 15 June, 2018)

Jones, A., Steinbach, R., Roberts, H., Goodman, A., Green, J., 2012. Rethinking passive transport: bus fare exemptions and young people's wellbeing. Health Place 18, 605-612.

https://doi.org/10.1016/i.healthplace.2012.01.003

Kelly, E., 2011. A ticket to Ride: Does Free Bus Travel Promote Active Ageing? University College London \& Institute for Fiscal Studies. London.

Kelly, P., Doherty, A., Mizdrak, A., Marshall, S., Kerr, J., Legge, A., Godbole, S., Badland, H., Oliver, M., Foster, C., 2014. High group level validity but high random error of a self-report travel diary, as assessed by wearable cameras. Journal of Transport \& Health 1, 190-201.

http://dx.doi.org/10.1016/i.jth.2014.04.003

King, A.C., Sallis, J.F., Frank, L.D., Saelens, B.E., Cain, K., Conway, T.L., Chapman, J.E., Ahn, D.K., Kerr, J., 2011. Aging in neighborhoods differing in walkability and income: associations with physical activity and obesity in older adults. Soc Sci Med 73, 1525-1533.

http://dx.doi.org/10.1016/i.socscimed.2011.08.032

Laverty, A.A., Mindell, J.S., Webb, E.A., Millett, C., 2013. Active travel to work and cardiovascular risk factors in the United Kingdom. Am J Prev Med 45, 282-288.

http://dx.doi.org/10.1016/j.amepre.2013.04.012

Liao, Y., Tsai, H.-H., Wang, H.-S., Lin, C.-P., Wu, M.-C., Chen, J.-F., 2016. Travel mode, transportationrelated physical activity, and risk of overweight in Taiwanese adults. Journal of Transport \& Health 3, 220-225. http://dx.doi.org/10.1016/j.jth.2016.02.012

Long, J.S., Freese, J., 2005. Regression Models for Categorical Dependent Variables Using Stata, 2nd ed. Stata Press, pp. 349-414.

Marmot, M., Atkinson, T., Bell, J., Black, C., Broadfoot, P., Cumberlege, J., 2010. Fair Society Healthy Lives - The Marmot Review. http://www.instituteofhealthequity.org/resources-reports/fair-societyhealthy-lives-the-marmot-review (accessed 5 April, 2016)

Marottoli, R., A., Leon, C.F.M., Glass, T., A., Williams, C.S., Cooney, L.M., Berkman, L.F., Tinetti, M.E., 1997. Driving Cessation and Increased Depressive Symptoms: Prospective Evidence from the New Haven EPESE. Journal of the American Geriatrics Society 45, 202-206.

https://doi.org/10.1111/j.1532-5415.1997.tb04508.x

Marottoli, R.A., de Leon, C.F.M., Glass, T.A., Williams, C.S., Cooney, J.L.M., Berkman, L.F., 2000. Consequences of Driving Cessation Decreased Out-of-Home Activity Levels. The Journals of Gerontology: Series B 55, S334-S340. https://doi.org/10.1093/geronb/55.6.S334

Mindell, J.S., Giampaoli, S., Goesswald, A., Kamtsiuris, P., Mann, C., Männistö, S., Morgan, K., Shelton, N.J., Verschuren, W.M.M., Tolonen, H., on behalf of the H. E.S. Response Rate Group., 2015. Sample selection, recruitment and participation rates in health examination surveys in Europe - 
experience from seven national surveys. BMC Medical Research Methodology 15, 78.

http://dx.doi.org/10.1186/s12874-015-0072-4

Morris, S., Humphrey, A., Byron, C., Templeton, I., Hurn, J., 2015. National Travel Survey 2014 -

Technical Report. The Department for Transport.

https://www.gov.uk/government/statistics/national-travel-survey-2014 (accessed 28 June, 2016)

Musselwhite, C.B., Shergold, I., 2013. Examining the process of driving cessation in later life. Eur J

Ageing 10, 89-100. https://doi.org/10.1007/s10433-012-0252-6

Office for National Statistics, 2011. Nomis Official Labour Market Statistics.

https://www.nomisweb.co.uk/census/2011/DC2101EW/view/2092957699?rows=c ethpuk11\&cols=

c age (accessed 1 March, 2016)

Paterson, D.H., Warburton, D.E., 2010. Physical activity and functional limitations in older adults: a systematic review related to Canada's Physical Activity Guidelines. Int J Behav Nutr Phys Act 7, 38.

http://dx.doi.org/10.1186/1479-5868-7-38

Patterson, R., Webb, E., Millett, C., Laverty, A.A., 2018. Physical activity accrued as part of public transport use in England. Journal of Public Health fdy099. https://doi.org/10.1093/pubmed/fdy099 Physical Activity Guidelines Advisory Committee, 2008. Physical Activity Guidelines for Americans. Department of Health and Human Services. http://health.gov/paguidelines/guidelines/ (accessed 26 February, 2016)

Ragland, D.R., Satariano, W.A., MacLeod, K.E., 2005. Driving Cessation and Increased Depressive Symptoms. The Journals of Gerontology: Series A 60, 399-403.

https://doi.org/10.1093/gerona/60.3.399

Reinhard, E., Courtin, E., van Lenthe, F.J., Avendano, M., 2018. Public transport policy, social engagement and mental health in older age: a quasi-experimental evaluation of free bus passes in England. J Epidemiol Commun H. https://doi.org/10.1136/jech-2017-210038

Secretary's Advisory Committee on National Health Promotion and Disease Prevention Objectives for 2020, 2010. Healthy People 2020: An Opportunity to Address Societal Determinants of Health in the U.S. https://www.healthypeople.gov/sites/default/files/SocietalDeterminantsHealth.pdf (accessed 2 Auguest, 2016)

Spinney, J.E.L., Scott, D.M., Newbold, K.B., 2009. Transport mobility benefits and quality of life: A time-use perspective of elderly Canadians. Transport Policy 16, 1-11.

http://dx.doi.org/10.1016/i.tranpol.2009.01.002

Taylor, B.D., Tripodes, S., 2001. The effects of driving cessation on the elderly with dementia and their caregivers. Accident Analysis \& Prevention 33, 519-528. https://doi.org/10.1016/S00014575(00)00065-8

Wanner, M., Gotschi, T., Martin-Diener, E., Kahlmeier, S., Martin, B.W., 2012. Active transport, physical activity, and body weight in adults: a systematic review. Am J Prev Med 42, 493-502.

https://doi.org/10.1016/i.amepre.2012.01.030

Webb, E., Laverty, A., Mindell, J., Millett, C., 2016. Free Bus Travel and Physical Activity, Gait Speed, and Adiposity in the English Longitudinal Study of Ageing. Am J Public Health 106, 136-141.

http://dx.doi.org/10.2105/AJPH.2015.302907

Webb, E., Netuveli, G., Millett, C., 2012. Free bus passes, use of public transport and obesity among older people in England. J Epidemiol Community Health 66, 176-180.

http://dx.doi.org/10.1136/jech.2011.133165

World Health Organization, 2002. Active Ageing - A policy Framework.

http://apps.who.int/iris/bitstream/10665/67215/1/WHO NMH NPH 02.8.pdf (accessed 20 July, 2016)

World Health Organization, 2010. Global Recommendations on Physical Activity for Health. http://apps.who.int/iris/bitstream/10665/44399/1/9789241599979 eng.pdf (accessed 4 March 2016)

World Health Organization, 2012. Action Plan for implementation of the European Strategy for the Prevention and Control of Noncommunicable Diseases 2012-2016 
http://www.euro.who.int/ data/assets/pdf file/0019/170155/e96638.pdf?ua=1 (accessed 14 April, 2016)

Yusuf, S., Reddy, S., Ôunpuu, S., Anand, S., 2001. Global burden of cardiovascular diseases part II: variations in cardiovascular disease by specific ethnic groups and geographic regions and prevention strategies. Circulation 104, 2855-2864. https://doi.org/10.1161/hc4701.099488 